\title{
Effector-Triggered and Pathogen-Associated Molecular Pattern-Triggered Immunity Differentially Contribute to Basal Resistance to Pseudomonas syringae
}

\author{
Jie Zhang, ${ }^{2}$ Haibin Lu, ${ }^{1,2}$ Xinyan Li, ${ }^{2,5}$ Yan Li, ${ }^{2}$ Haitao Cui, ${ }^{2}$ Chi-Kuang Wen, ${ }^{3}$ Xiaoyan Tang, ${ }^{5}$ Zhen Su, \\ and Jian-Min Zhou ${ }^{2}$ \\ ${ }^{1}$ College of Life Sciences, Peking University, Beijing, China; ${ }^{2}$ National Institute of Biological Sciences, Beijing, China; \\ ${ }^{3}$ Shanghai Institute of Biological Sciences, Chinese Academy of Sciences, China; ${ }^{4}$ State Key Laboratory of Plant Physiology \\ and Biochemistry (SKLPPB), College of Biological Sciences, China Agricultural University, China; ${ }^{5}$ Department of Plant \\ Pathology, Kansas State University, Manhattan, KS, U.S.A.
}

Submitted 2 December 2009. Accepted 23 March 2010.

Pathogens induce pathogen-associated molecular pattern (PAMP)-triggered immunity (PTI) and effector-triggered immunity (ETI) in plants. PAMPs are microbial molecules recognized by host plants as nonself signals, whereas pathogen effectors are evolved to aid in parasitism but are sometimes recognized by specific intracellular resistance proteins. In the absence of detectable ETI determining classical incompatible interactions, basal resistance exists during compatible and nonhost interactions. What triggers the basal resistance has remained elusive. Here, we provide evidence that ETI contributes to basal resistance during both compatible and nonhost Arabidopsis-Pseudomonas syringae interactions. Mutations in $R A R 1$ and $N D R 1$, two genes required for ETI, compromise basal resistance in both compatible and nonhost interactions. Complete nonhost resistance to $P$. syringae pv. tabaci required a functional type III secretion system. PTI appears to play a greater role in nonhost resistance than basal resistance during compatible interactions, because abrogation of PTI compromises basal resistance during nonhost but not compatible interactions. Strikingly, simultaneous abrogation of ETI and flagellin-induced PTI rendered plants completely susceptible to the nonadapted bacterium $P$. syringae pv. tabaci, indicating that ETI and PTI act synergistically during nonhost resistance. Thus, both nonhost resistance and basal resistance to virulent bacteria can be unified under PTI and ETI.

As an abundant nutrient reservoir, plants are naturally exploited by microbes in their surroundings. An essential element in the evolution of land plants is to develop effective defenses against a wide range of potentially harmful microbes. Some pathogenic microbes manage to overcome the initial defense barrier and succeed in the colonization and infection of their host plants. This applies a selection pressure on the plant to drive a new round of evolution for resistance that, in turn, spurs further evolution in the pathogen for new virulence (Jones and Dangl 2006). Therefore, disease resistance in a nor-

J. Zhang and $\mathrm{H}$. Lu contributed equally to this work.

Corresponding author: J.-M. Zhou; E-mail: zhoujianmin@nibs.ac.cn

* The $\boldsymbol{e}$-Xtra logo stands for "electronic extra" and indicates that three supplementary tables and one supplementary figure are published online. mal plant is likely composed of multiple layers of defenses laid down over a long history of plant-microbe association. Conversely, an adapted pathogen must effectively overcome host resistance to enable its infection of a given plant. Plant immunity to pathogens can be induced upon the perception of relatively conserved pathogen- or microbe-associated molecular patterns (PAMPs or MAMPs) through cell surface receptors (Ausubel 2005; Chisholm et al. 2006). Many pathogenic microbes are capable of delivering effector proteins into the host cell to enhance virulence, often by inhibiting PAMP-triggered immunity (PTI). Some of these effectors are recognized by corresponding plant disease resistance proteins in a cultivarspecific manner to activate effector-triggered immunity (ETI). ETI often, but not always, result in hypersensitive response (HR), characterized by cell death (Ausubel 2005; Jones and Dangl 2006). It is thought that PTI and ETI are sequentially evolved to counter the co-evolving pathogens (Kang et al. 2003; Nürnberger and Lipka 2005; Jones and Dangl 2006). Modern-day pathogens have acquired effectors to collectively overcome PTI and ETI in their host plants.

According to the outcome, interactions between plants and pathogenic bacteria can be classified as compatible, incompatible, and nonhost interactions. Incompatible interactions are cultivar-specific and determined by ETI. In contrast, compatible interactions are thought to lack ETI. Mutations in effector genes or cognate plant resistance genes or plant genes required for ETI convert the otherwise incompatible interactions into compatible ones. Nonhost interactions refer to those between a plant species and nonadapated pathogens (Thordal-Christensen 2003). Some effectors from nonadapted pathogens also trigger ETI and induce HR, typically seen in the incompatible interactions. For example, HopQ1-1 of the DC3000 strain of Pseudomonas syringae pv. tomato triggers HR in Nicotiana benthamiana, a nonhost plant (Wei et al. 2007). Deletion of hopQ1-1 from DC3000 converts this nonadapted bacterium into a strain fully virulent on $N$. benthamiana, indicating a decisive role of ETI in this nonhost interaction. However, a clear role of ETI in overall resistance during other nonhost interactions has not been established. For instance, the PT23 strain of $P$. syringae pv. tomato, a nonadapted bacterium on soybean, carries four effector genes ( $a v r A, a v r D, a v r E$, and $a v r P t o$ ), each capable of inducing HR and disease resistance in soybean in a cultivardependent manner (Lorang et al. 1994). Simultaneous deletion of all four avirulence (avr) genes failed to alter the nonhost interaction either qualitatively or quantitatively. 
In the absence of recognizable ETI, a weak but detectable inducible resistance exists in both nonhost and compatible interactions. This resistance has been referred to as basal resistance. PTI is known to contribute to basal resistance (Boller and Felix 2009). As a result, PTI and basal resistance have been used interchangeably in the literature. However, it is fully possible that weak ETI could also contribute to basal resistance.

We and others have shown previously that PAMP-induced defenses play an important role in nonhost resistance to $P$. $s y$ ringae ( $\mathrm{Li}$ et al. 2005; Truman et al. 2006). The lack of the flagellin-coding gene $f l i C$ in the $P$. syringae pv. tabaci strain compromises Arabidopsis nonhost resistance to P. syringae pv. tabaci ( $\mathrm{Li}$ et al. 2005). However, the flagellin-mediated resistance only accounts for partial resistance to $P$. syringae pv. tabaci ( $\mathrm{Li}$ et al. 2005). Therefore, additional defense layers may exist for highly effective resistance against nonadapted bacteria. Alternatively, nonadapted bacteria may lack compatibility factors required to be a pathogen in nonhost plants. In the case of compatible interactions, PTI is largely ineffective, at least when bacteria are infiltrated into the apoplast (Zipfel et al. 2004; Li et al. 2005; Melotto et al. 2006). It remains to be determined to what extent PTI and ETI contribute to basal resistance to compatible and nonadapted bacteria.

Here, we provide evidence that PTI and ETI differentially contribute to basal resistance to multiple strains of $P$. syringae bacteria that are either virulent or nonpathogenic on Arabidopsis. Arabidopsis mutants rarl and ndrl are compromised in resistance to two strains of $P$. syringae pv. tabaci but not $P$. syringae pv. phaseolicola. The rarl mutant also exhibits enhanced disease susceptibility to DC3000. Consistent with a role of effector-triggered defenses, the $R A R l$-mediated resistance to $P$. syringae pv. tabaci and DC3000 required a type III secretion system (TTSS). The involvement of effector-triggered defenses in DC3000 resistance was further supported by microarray analysis. The expression of a significant portion of Arabidopsis defense-related genes are enhanced by TTSS in DC3000 and $R A R I$ in plants. Furthermore, the $P$. syringae pv. tabaci mutant lacking fliC is highly virulent on rarl or $n d r l$ mutant plants, suggesting that PAMP-triggered defenses and effector-triggered defenses act synergistically to restrict this nonadapted bacterium. These results collectively support the idea that PTI and ETI together account for basal resistance to various $P$. syringae bacteria and suggest that the effectiveness of PTI and ETI determines nonhost and compatible interactions.

\section{RESULTS}

\section{RAR1 and NDR1 are differentially required}

\section{for basal resistance to various $P$. syringae strains.}

To determine the contribution of PTI and ETI in Arabidopsis basal resistance to various compatible and nonadapted $P$. syringae bacteria, we systematically analyzed four $P$. syringae strains belonging to three pathovars: $P$. syringae pv. tomato DC3000, $P$. syringae pv. tabaci R1152, P. syringae pv. tabaci 6505, and $P$. syringae pv. phaseolicola NPS3121. Arabidopsis is a highly susceptible host to DC3000 but is a nonhost plant to the other three strains.

We first determined bacterial growth on rarl and $n d r l \mathrm{mu}-$ tant plants. Both the HSP90 co-chaperone RAR1 and the membrane protein NDR1 are known to be required for ETI during incompatible interactions (Jones and Dangl 2006). NDR1 is known to play a role in basal resistance to DC3000, because the $n d r l$ mutant displays enhanced disease susceptibility whereas overexpression of NDR1 enhances resistance to this strain (Coppinger et al. 2004). However, the role of RAR1 in DC3000 basal resistance has been controversial, because one report indicated normal susceptibility while another suggested enhanced disease susceptibility in the rarl-20 mutant (Warren et al. 1999; Holt et al. 2005). A role of RAR1 and NDR1 in nonhost resistance to $P$. syringae has not been tested. We independently tested two rarl mutants, rarl-20 and rarl29, for basal resistance to DC3000. Mutant rarl-29 is an ethyl methanesulphonate (EMS)-generated allele carrying a point mutation in the CHORD II domain that disrupts the interaction with SGT1 (Shang et al. 2006). In repeated experiments, DC3000 bacteria grew to a 20- to 50-fold higher population in the two mutants (Fig. 1A). Both rarl mutations increased the growth in Arabidopsis of P. syringae pv. tabaci R1152 by approximately 10-fold (Fig. 1B). The rarl mutations also increased the growth of $P$. syringae pv. tabaci 6505 in three independent experiments (Fig. 1C). However, the increase was relatively small (three- to fourfold), although the rarl-29 mutation nearly abolished the $P$. syringae pv. tabaci $6505-$ induced HR (Table 1). The EMS mutant rarl-29 showed similar or greater susceptibility than the deletion mutant rarl-20. Therefore, the rarl-29 mutant was used in the rest of experiments described in this article. In contrast to the other three strains, $P$. syringae pv. phaseolicola NPS3121 did not grow and had indistinguishable bacterial populations on either wildtype (WT) or rarl-29 plants (Fig. 1D). We also tested bacterial growth on $n d r l$ mutant plants. The $n d r l$ mutation compromised resistance to $P$. syringae pv. tabaci $\mathrm{R} 1152$ and $P$. syringae pv. tabaci 6505 but not $P$. syringae pv. phaseolicola NPS3121 (Fig. 1E). Together, these results indicate that RAR1 and NDR1 are differentially required for basal resistance to the four $P$. syringae strains, suggesting that the RAR1- and NDR1dependent ETI contributes to basal resistance to DC3000, $P$. syringae pv. tabaci R1152, and $P$. syringae pv. tabaci 6505 but not $P$. syringae pv. phaseolicola NPS3121.

RAR1-dependent resistance is mediated by TTSS function.

To test whether TTSS effector-mediated defenses collectively contribute to resistance to $P$. syringae pv. tabaci 6505, we generated an $h r c C^{-}$strain by inserting a truncated $h r c C$ gene into TOPO vector and introduced the construct into $P$. syringae pv. tabaci 6505 through homologous recombination. HrcC is an essential structural protein of the $P$. syringae TTSS. We tested the resulting mutant for its ability to induce HR. As expected, the $h r c C^{-}$strain was completely impaired in HR induction (Table 1; Supplementary Fig. S1), an observation that is consistent with the known function of $\mathrm{HrcC}$. The $h r c C^{-}$strain was next compared with WT P. syringae pv. tabaci 6505 for the ability to multiply in WT plants. The mutant strain consistently grew more than WT 6505 (Fig. 2A), supporting the idea that TTSS effectors of this strain contributed to overall resistance in Arabidopsis. We also tested the WT P. syringae pv. phaseolicola NPS3121 and an NPS3121 hrpA mutant for growth on WT plants. Both the WT $P$. syringae pv. phaseolicola NPS3121 and the hrpA mutant had indistinguishable bacterial populations in plants (Fig. 2B), suggesting that NPS3121 TTSS effectors do not collectively contribute to virulence or resistance. However, it still is possible that these effectors may individually play a role in bacterial virulence or trigger ETI responses in Arabidopsis.

To further test whether the RAR1-dependent basal resistance to DC3000 and P. syringae pv. tabaci 6505 resulted from ETI, we determined the impact of a DC3000 hrpL mutation (Zwiesler-Vollick et al. 2002) and a $6505 \mathrm{hrcC}$ mutation on $R A R l$-dependent resistance. $\mathrm{HrpL}$ is a transcription regulator required for the transcription of TTSS genes. The DC3000 $\mathrm{hrpL}^{-}$ strain had indistinguishable populations in WT and rarl-29 plants (Fig. 2C). Similarly, the P. syringae pv. tabaci 6505 hrc $C^{-}$ strain also had indistinguishable populations on WT and rarl 
plants (Fig. 2D). The results indicate that RAR1 does not impact plant resistance to $P$. syringae TTSS mutants, supporting the proposal that the RAR1-dependent basal resistance to DC3000 and 6505 is triggered by TTSS-delivered effectors.

Role of Arabidopsis RARI and P. syringae pv. tabaci hrcC in defense gene induction.

ETI in Arabidopsis is associated with a strong induction of $P R 1$ gene expression. Although PTI also induces PR1, the induction is significantly weaker. The WT $P$. syringae pv. tabaci 6505 induced a strong $P R I$ expression in the WT plants (Fig. 3A). Mutations in either the bacterial $h r c C$ gene or Arabidopsis $R A R l$ gene greatly reduced $P R l$ expression. We also tested the expression of three PAMP-induced genes, FRK1, WRKY22, and NHO1 (Asai et al. 2002; Li et al. 2005). All three genes were significantly induced by $P$. syringae pv. tabaci 6505 inoculation. The rarl-29 mutation in Arabidopsis and $h r c C$ mutation in strain 6505 had no discernable effect on

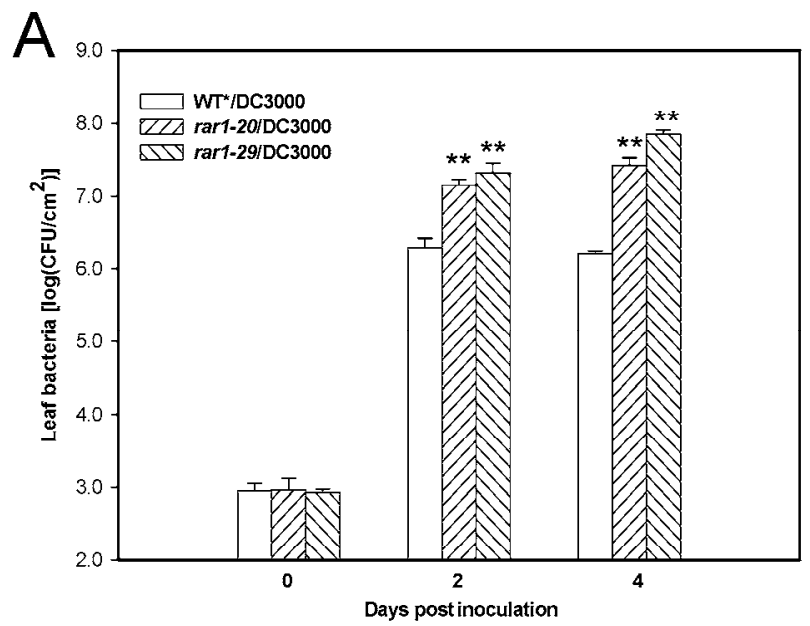

B
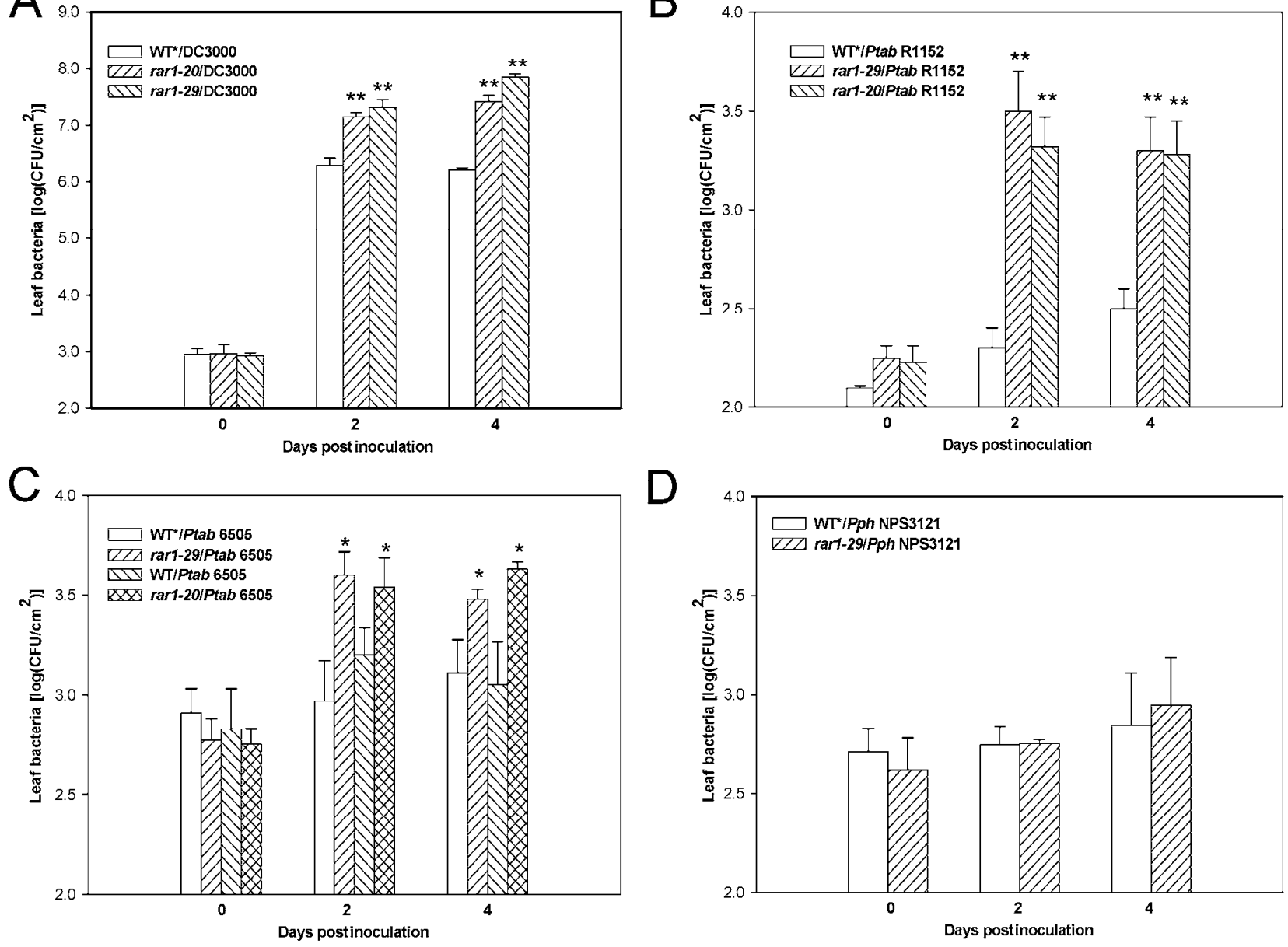

D
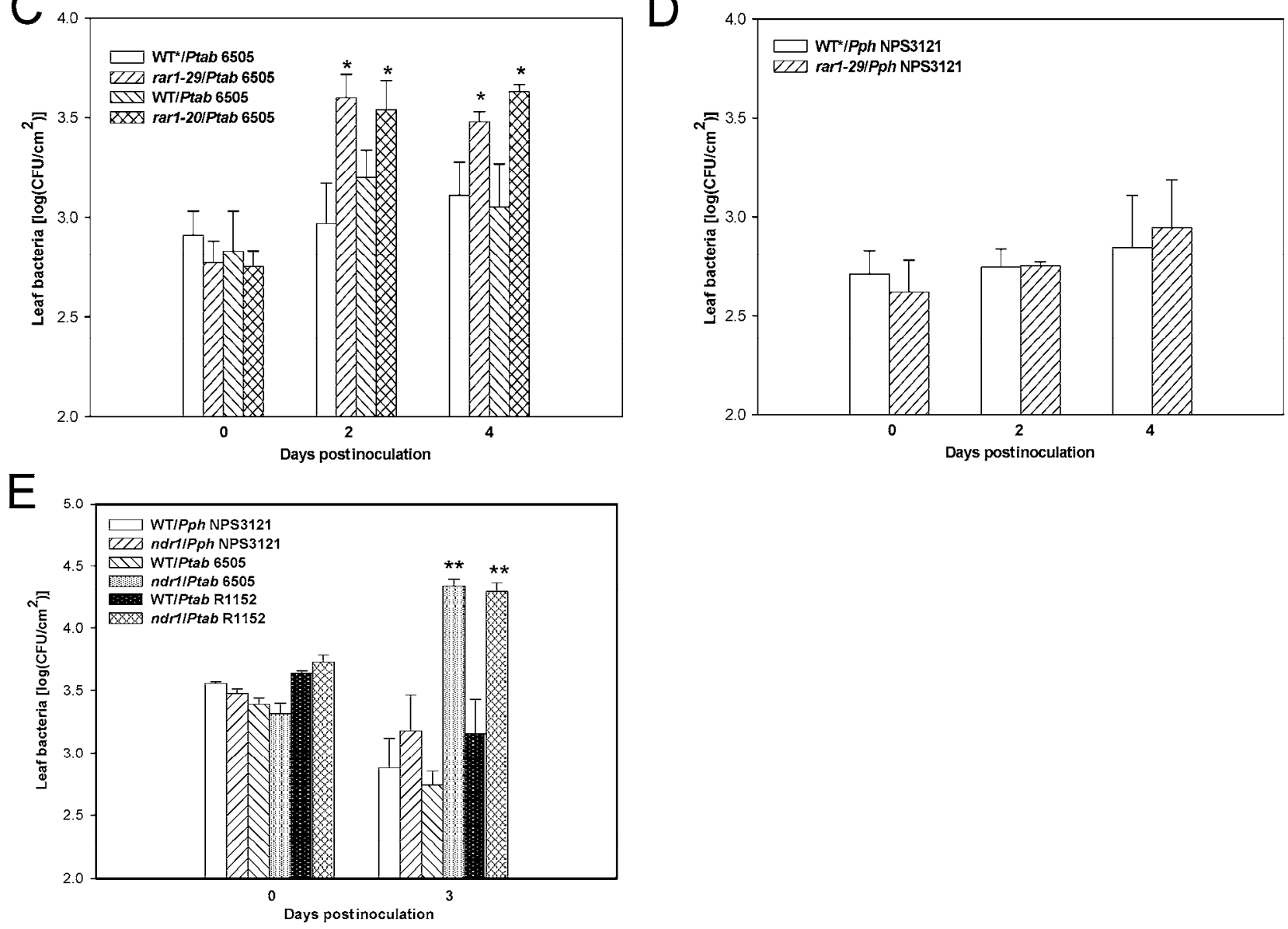

Fig. 1. RAR1 and NDR1 are differentially required for basal resistance during compatible and nonhost interactions. A, Multiplication of DC3000 bacteria in wild-type (WT)* and rarl mutants. B, Multiplication of Pseudomonas syringae pv. tabaci R1152 in WT* and rarl mutants. C, Multiplication of P. syringae pv. tabaci 6505 in WT, WT*, rarl-20, and rarl-29 mutants. D, Multiplication of P. syringae pv. phaseolicola NPS3121 in WT* and rarl-29 mutant. E, Multiplication of $P$. syringae pv. tabaci R1152, P. syringae pv. tabaci 6505, and P. syringae pv. phaseolicola NPS3121 in WT and ndrl mutant plants. The WT* and $\operatorname{rar} 1-29$ plants contain a RAP2.6 reporter gene. Error bars indicate standard deviation. Student's $t$ test was carried out to determine the significance of difference; $*$ and $* *$ indicate significant difference at $P<0.05$ and 0.01 , respectively. Experiments were repeated three times with similar results. 
the three PAMP-induced genes tested (Fig. 3A). These results suggested that, whereas $R A R 1$ and TTSS function are required for effector-triggered defense gene expression, they are dispensable for PAMP-induced gene expression. To further test this possibility, we treated WT and rarl-29 plants with flg22 and determined the expression of FRK1, WRKY22, and NHO1 (Fig. 3B). As expected, both WT and rarl-29 plants showed similar induction of the three tested genes.

\section{Microarray analysis of PAMP-induced and effector-induced defenses in response to $\mathrm{DC} 3000$.}

To investigate the role of TTSS function in PAMP- and effector-triggered defense gene expression in response to DC3000, we examined public microarray databases for genes regulated by WT and $h r c C^{-} \mathrm{DC} 3000$ and $P$. syringae pv. phaseolicola NPS3121 (included as a nonhost control). A twofold increase or decrease at a $P$ value of 0.05 was used as criteria for differentially expressed genes. Genes up- or downregulated by these strains were compared with 1,928 flg22-inducible genes identified in previous reports (Navarro et al. 2004; Qutob et al. 2006; Chen et al. 2009) (Supplementary Tables S1 and S2). At $2 \mathrm{~h}$ after bacterial inoculation, different $P$. syringae strains, either virulent or nonpathogenic, behaved similarly and induced approximately 250 to 440 genes. The vast major- ity ( 80 to $89 \%$ ) of these genes were flg22-inducible genes, more than 200 of which were induced by all three strains. This expression pattern remained steady over the course of $24 \mathrm{~h}$ for P. syringae pv. phaseolicola NPS3121 and the DC3000 hrcC strain. However, the WT DC3000-treated tissues showed dramatically distinct gene expression profiles at 6 and $24 \mathrm{~h}$. WT DC3000 induced only 43 flg22-inducible genes at $6 \mathrm{~h}$, down from 249 at $2 \mathrm{~h}$. A comparison between the WT DC3000 and DC3000 $\mathrm{hrCC}^{-}$strain showed that 416 genes were repressed by DC3000 TTSS at $6 \mathrm{~h}$. Among these, 334 were flg22 inducible,

Table 1. Strain Pseudomonas syringae pv. tabaci 6505 induces hypersensitive response in an $h r c C$ - and $R A R 1$-dependent manner ${ }^{a}$

\begin{tabular}{lrrr}
\hline Plant, strain $^{\mathbf{b}}$ & $\mathbf{9 h}$ & $\mathbf{1 2} \mathbf{h}$ & $\mathbf{2 4} \mathbf{h}$ \\
\hline Wild type (WT) & & & \\
WT & $9 / 18$ & $16 / 18$ & $16 / 18$ \\
hrc $^{-}$ & $0 / 18$ & $0 / 18$ & $0 / 18$ \\
fliC $^{-}$ & $15 / 18$ & $18 / 18$ & $18 / 18$ \\
rarl-29 & & & \\
WT & $0 / 18$ & $0 / 18$ & $3 / 18$ \\
hrc & $0 / 18$ & $0 / 18$ & $0 / 18$ \\
fliC $^{-}$ & $0 / 18$ & $3 / 18$ & $10 / 18$ \\
\hline
\end{tabular}

a Shown are numbers of collapsed leaves out of a total of 18 infiltrated leaves.
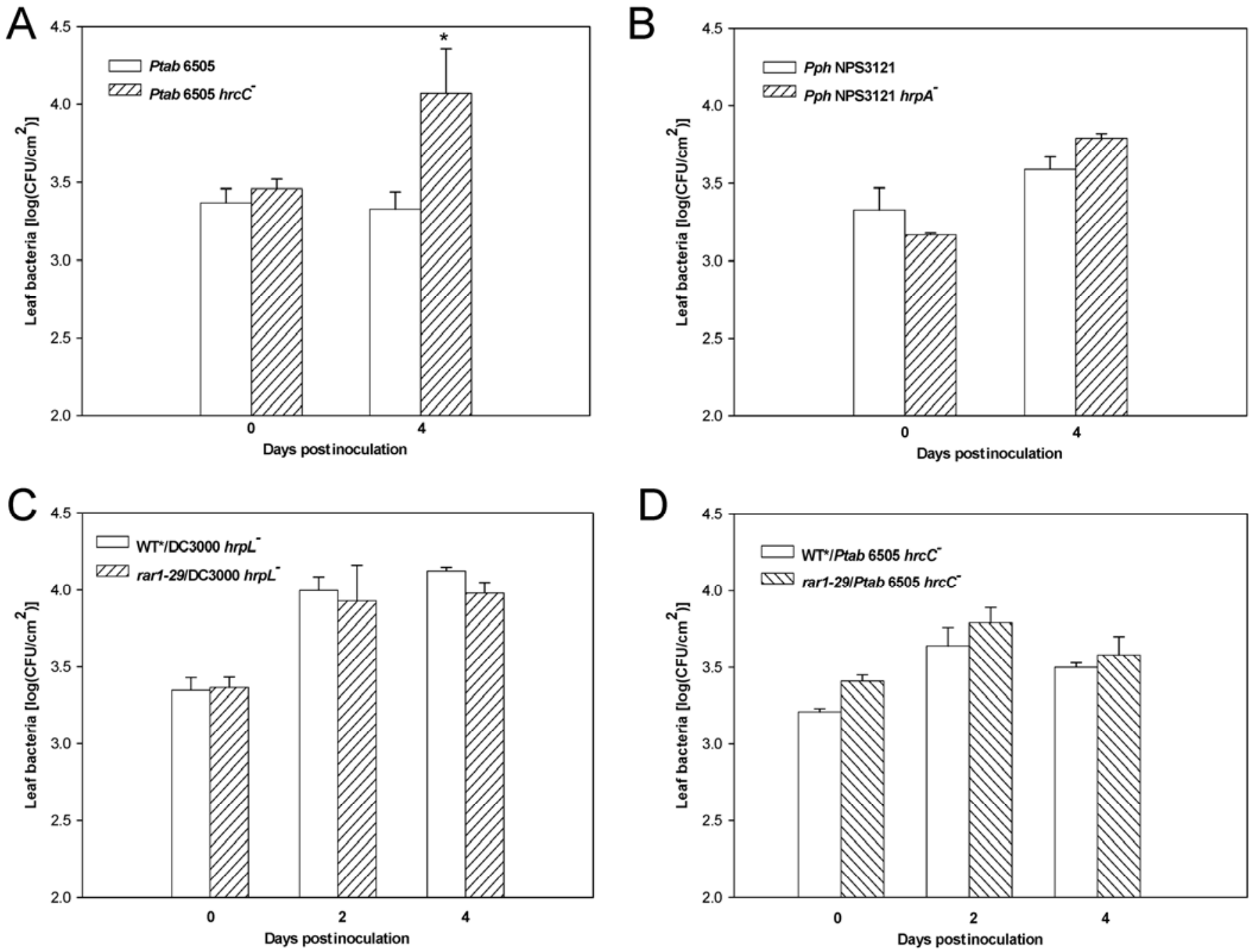

Fig. 2. Type III secretion system contributes to resistance to Pseudomonas syringae pv. tabaci 6505 but not P. syringae pv. phaseolicola NPS3121. A, Multiplication of P. syringae pv. tabaci 6505 wild type (WT) (Ptab 6505) and hrc $C^{-}$(Ptab 6505 hrc ${ }^{-}$) in Arabidopsis plants. B, Multiplication of P. syringae pv.

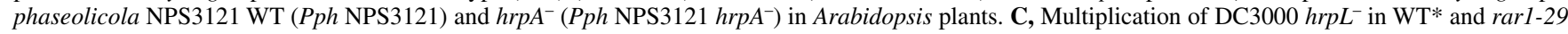
plants. D, Multiplication of $P$. syringae pv. tabaci $6505 \mathrm{hrcC}^{-}$in WT* and rarl-29 plants. Error bars indicate standard deviation. Student's $t$ test was carried out to determine the significance of difference. Results shown are representative of three independent experiments. 
confirming that a major function of DC3000 TTSS is to suppress PAMP signaling in plants.

A close examination indicated a complex pattern of gene expression in the DC 3000 -treated tissues at $24 \mathrm{~h}$. As expected for the virulence function, DC3000 TTSS repressed 1,502 genes, including 284 flg22-inducible genes. Interestingly, DC3000 TTSS also induced 1,483 genes, including 328 flg22-inducible genes. Thus, it appears that some flg22-induced genes were suppressed while others were induced by the DC3000 TTSS effectors.

Some of the DC3000-induced genes at $24 \mathrm{~h}$ may have resulted from weak ETI. Alternatively, they may be indirectly induced by stress caused by disease-related physiological changes. To further determine the involvement of effector-triggered defenses at $24 \mathrm{~h}$, we carried out additional microarray analysis by comparing gene expression in WT and rarl-29 plants $24 \mathrm{~h}$ after WT DC3000 inoculation. The experiment consisted of three independent biological replicates. Correlation analysis showed that the three biological replicates were $\geq 95 \%$ similar. In total, 154 genes were upregulated when WT plants were compared with the rarl-29 mutant (Supplementary Table S3). At least 43 of these genes encode proteins with apparent roles in disease resistance and included $N D R 1$, NHO1, NPR1/NIM1 interacting protein gene NIMIN-1, and genes encoding receptor-like kinases, nucleotide-binding site leucine-rich repeat resistance proteins, WRKYs, and pathogenesis-related (PR) proteins. Of the 154 upregulated genes, $95(62 \%)$ were flg22 inducible, indicating that genes induced downstream of RAR1 largely overlap with PAMP-induced genes. Consistent with the idea that some DC3000 effectors trigger RAR1-dependent defenses, 18 DC3000 TTSS-induced genes were induced in a RAR1-dependent manner. Even among the 284 flg22-inducible genes that were repressed by DC3000 TTSS, 22 were less repressed in WT plants compared with rarl-29 plants. These results support the idea that some DC3000 effectors trigger or enhance the expression of defense-related genes, including flg22-inducible genes, in an RAR1-dependent manner.

\section{Inhibition of PAMP-signaling pathway compromises} nonhost resistance but not basal resistance to $\mathrm{DC3000}$.

We previously showed that the lack of the flagellin-encoding gene fliC in $P$. syringae pv. tabaci 6505 resulted in partial loss of nonhost resistance in Arabidopsis, indicating that PAMPinduced defenses contribute to nonhost resistance to 6505 ( $\mathrm{Li}$ et al. 2005). However, because the bacterium carries multiple PAMPs, the $\mathrm{fliC}^{-}$strain is likely to trigger a partial PTI response. Mitogen-activated protein kinases (MAPK) play a central role in immunity by integrating signals from various PAMPs (Zipfel 2009). We previously identified an effector, HopAI1, from $P$. syringae pv. tomato that targets MAPK (Li et al. 2005; Zhang et al. 2007). Transgenic plants expressing HopAI1 are largely abolished in PTI defenses. Therefore, we further examined growth of $P$. syringae pv. phaseolicola NPS3121 and P. syringae pv. tabaci 6505 bacteria in HopAII transgenic plants. Transgenic expression of HopAII enhanced

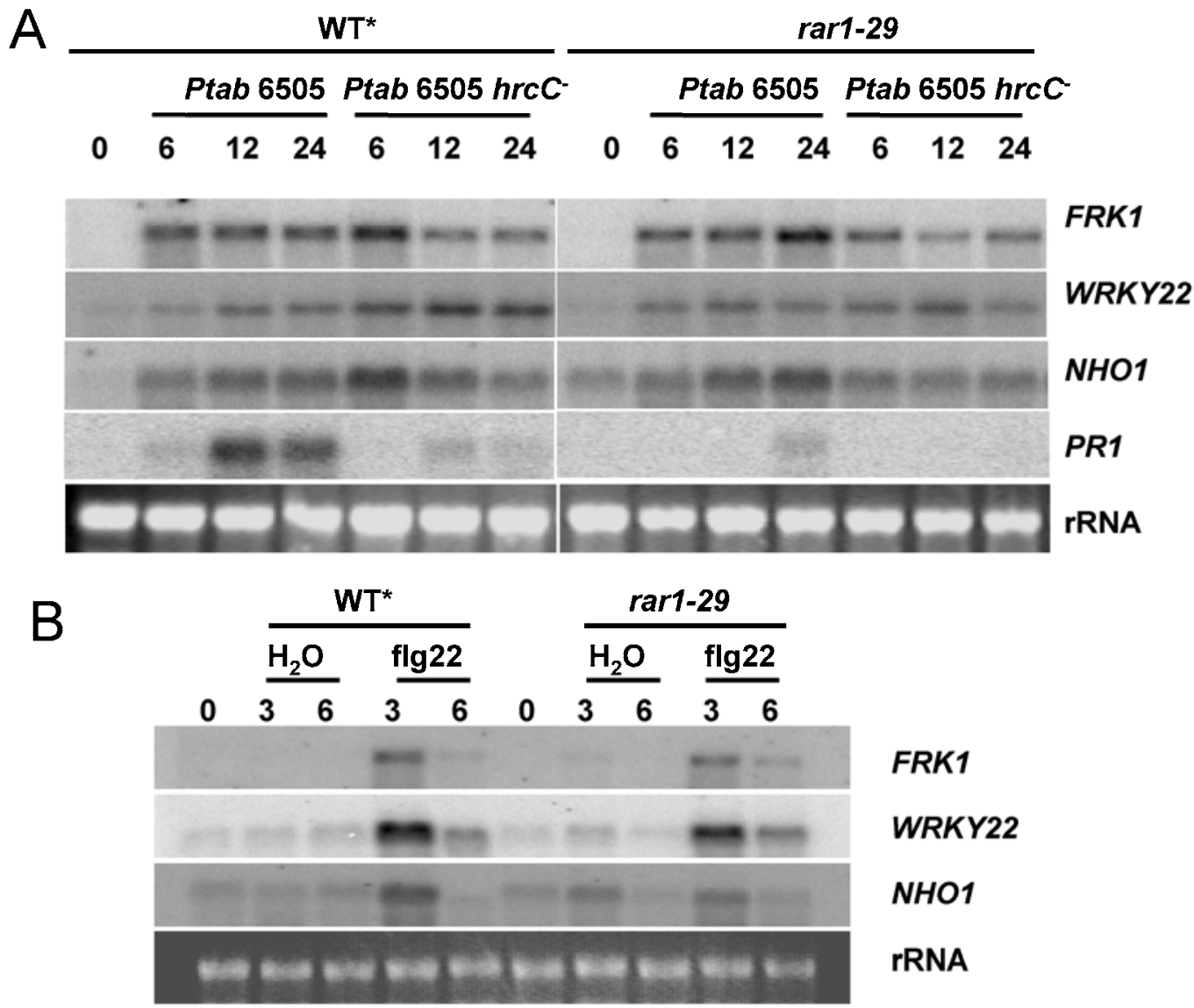

Fig. 3. Bacterial type III secretion system and plant $R A R 1$ are required for $P R 1$ induction but not pathogen-associated molecular pattern (PAMP)-induced genes. A, Northern blot analysis of gene expression in response to bacterial inoculation. Wild-type (WT)* and rarl-29 plants treated with Pseudomonas syringae pv. tabaci 6505 WT (Ptab 6505) or the $h r c C$ mutant (Ptab 6505 hrc $^{-}$) bacteria were collected at the indicated times before RNA isolation. RNA blots were hybridized with the indicated probes. Equal loading of RNA was indicated by a representative ethidium-bromide-stained gel. B, Northern blot analysis of PAMP-induced genes in WT* and rarl-29 plants. Plants infiltrated with $1 \mu \mathrm{M}$ flg22 were collected at the indicated times, and RNA was isolated for Northern analysis. 
bacterial populations of the two strains by 50- to 200-fold (Fig. 4A). Although a potential suppression of ETI by HopAI1 cannot be ruled out, these results are consistent with an important role of PAMP-mediated defenses in nonhost resistance to both $P$. syringae pv. phaseolicola and $P$. syringae pv. tabaci.

Previous reports indicated that FLS2 signaling contributes to pre-penetration resistance to DC3000 (Zipfel et al. 2004; Melotto et al. 2006). We tested whether the inhibition of the MAPK pathway compromised basal resistance to DC3000. DC3000 grew similarly in WT plants and transgenic plants expressing HopAII (Fig. 4B). Because all of our inoculation experiments were done by syringe infiltration, the result suggested that PAMP-signaling does not contribute to post-penetration resistance to DC3000 in the apoplast. This is also consistent with our earlier finding that depletion of the $\mathrm{fliC}$ gene in DC3000 did not enhance its growth on Arabidopsis when the bacteria were infiltrated into leaves ( $\mathrm{Li}$ et al. 2005).

\section{ETI and PTI synergistically contribute}

to Arabidopsis nonhost resistance to $P$. syringae pv. tabaci.

Results described above indicate that abrogation of either PTI or ETI leads to a partial loss of resistance to $P$. syringae pv. tabaci 6505. To test the possibility that PTI and ETI act
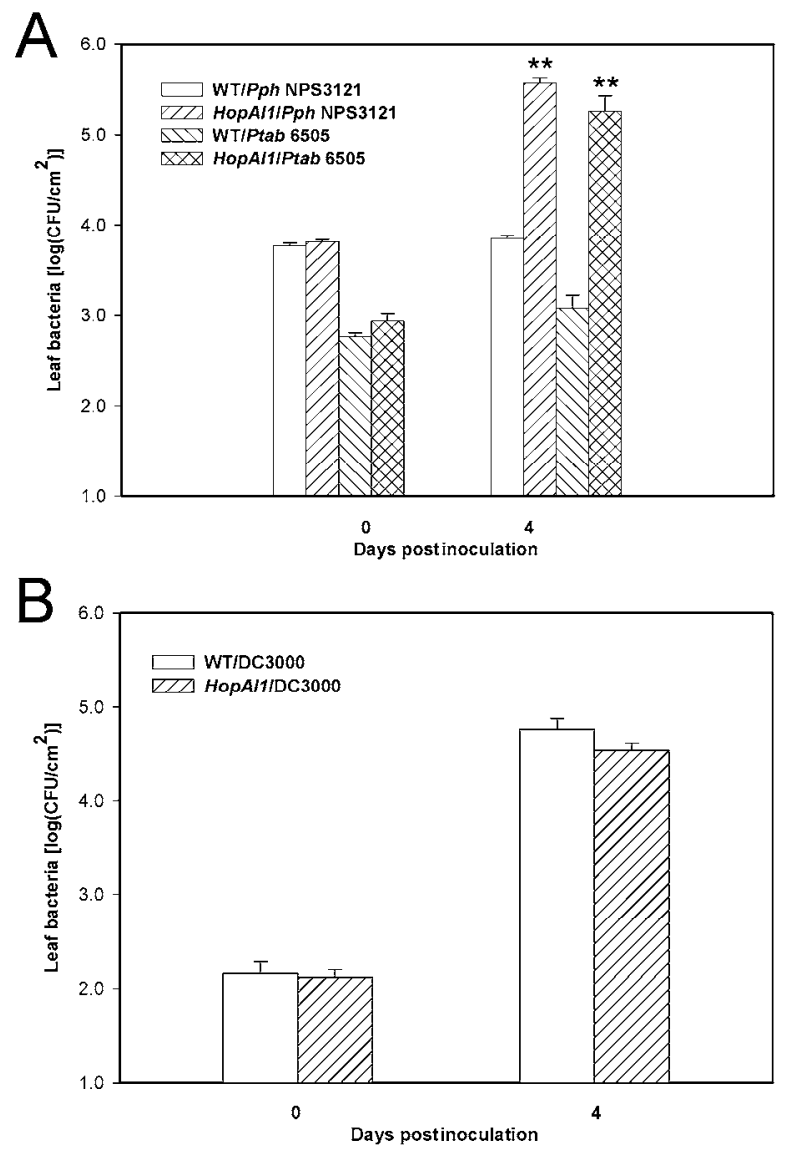

Fig. 4. Inhibition of pathogen-associated molecular pattern (PAMP) signaling by HopAII transgene compromises nonhost resistance but not basal resistance during a compatible interaction. A, Multiplication of Pseudomonas syringae pv. tabaci 6505 or P. syringae pv. phaseolicola NPS3121 in wild-type (WT) and HopAII transgenic plants. B, Multiplication of DC3000 in WT and HopAII transgenic plants. Plants were treated with 40 $\mu \mathrm{M}$ estradiol for $24 \mathrm{~h}$ before being inoculated with the indicated strains for bacterial growth assay. Error bars indicate standard deviation. Student's $t$ test was carried out to determine the significance of difference; $*$ and $* *$ indicate significant difference at $P<0.05$ and 0.01 , respectively. A lower inoculum $\left(10^{5} \mathrm{CFU} / \mathrm{ml}\right)$ was used in this experiment. Experiments were repeated twice with similar results. synergistically in nonhost resistance to this bacterium, we examined the impact of the lack of flagellin-dependent defenses and RAR1- or NDR1-dependent defenses on overall resistance to strain 6505 . The $\mathrm{fli}^{-}$strain grew by approximately 1,000 fold in either the rarl-29 or ndrl mutant plants, a level similar to compatible interactions (Fig. 5A and B). These results indicate that ETI and PTI in combination account for most of the plants' resistance to this nonhost bacterium. We have previ-
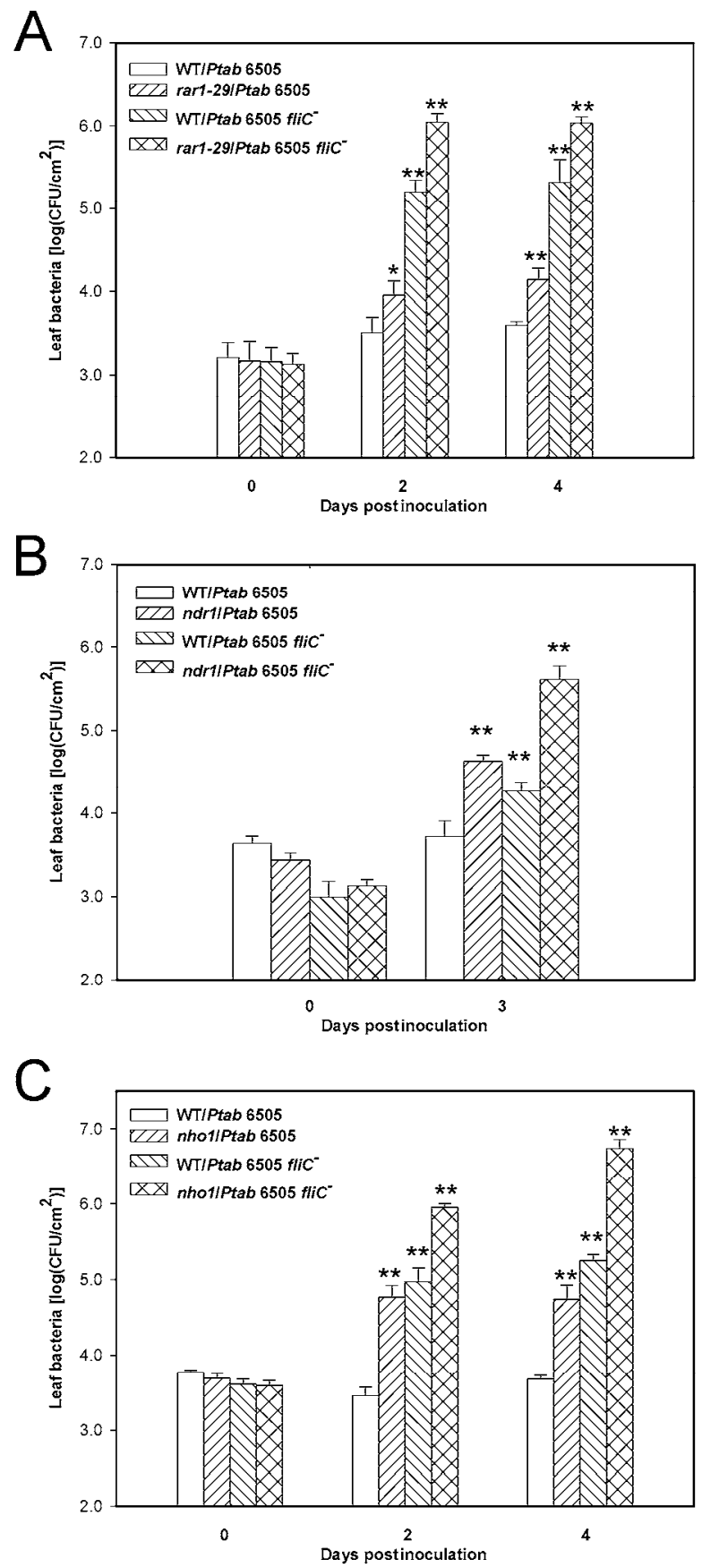

Fig. 5. Pathogen-associated molecular pattern (PAMP)-triggered immunity (PTI) and effector-triggered immunity (ETI) synergistically contribute to nonhost resistance to Pseudomonas syringae pv. tabaci 6505 (Ptab 6505). The $f_{l i C^{-}}$strain is fully virulent on $\mathbf{A}, \operatorname{rarl}-29$ plants; $\mathbf{B}, n d r 1$ plants; and C, nhol plants. WT (Ptab 6505) or fliC ${ }^{-}$(Ptab 6505 fliC $^{-}$) bacteria were infiltrated into $\mathrm{WT}^{*}, \operatorname{rarl} 1-29$, WT, or nhol plants, and leaf bacterial populations were determined at the indicated times. Error bars indicate standard deviation. Student's $t$ test was carried out to determine the significance of difference; * and $* *$ indicate significant difference at $P<0.05$ and 0.01 , respectively. Experiments were repeated three times with similar results. 
ously shown that $\mathrm{NHOl}$, a gene acting downstream of both ETI and PTI, is required for resistance to a broad range of nonhost, nonpathogenic, or incompatible $P$. syringae strains (Kang et al. 2003; Li et al. 2005). nhol is only partially susceptible to the WT $P$. syringae pv. tabaci 6505 but the fli $^{-}$strain grew by nearly 2,000-fold on the nhol plants (Fig. 5C), further supporting the synergistic effect of PTI and ETI in resistance to this $P$. syringae strain.

\section{DISCUSSION}

In this study, we demonstrate that PTI and ETI differentially contribute to basal resistance during compatible and nonhost interactions. Our data showed that ETI quantitatively contributes to nonhost resistance to $P$. syringae pv. tabaci 6505 and $P$. syringae pv. tabaci R1152. Both RAR1 and NDR1 are required for resistance to these strains. Supporting the possibility that the $R A R l$-dependent resistance corresponded to ETI, the $h r c C$ mutation of strain 6505 and rarl mutation in plants had virtually the same effects: a diminished $P R-1$ induction, abolished $\mathrm{HR}$, and a three- to fivefold increase of bacterial population in plants. Furthermore, $6505 \mathrm{hrcC}^{-}$had equal bacterial populations in rarl and WT plants. Ham and associates (2007) showed that inoculation of Arabidopsis with $P$. syringae pv. phaseolicola NPS3121 induced both PTI and ETI responses. In our study, neither RARl nor NDRl is required for resistance to strain NPS3121. Although a role of ETI cannot be ruled out completely, the data are consistent with a lesser role of ETI in this particular nonhost interaction.

Our results also showed that basal resistance to DC3000, a compatible strain on Arabidopsis, is primarily caused by weak ETI. This conclusion is supported by the following findings. $R A R l$ and $N D R l$ are required for limiting the growth of DC3000, and RAR1 is not required for resistance to DC3000 $h r p L^{-}$. Effectors from DC3000 are known to suppress PTI and ETI (Espinosa et al. 2003; Li et al. 2005; Guo et al. 2009). Microarray analysis indicated that DC3000 TTSS also induce defenses, likely through a subset of effectors. At $6 \mathrm{~h}$ after inoculation, DC3000 TTSS predominantly suppresses genes normally induced by flg22. However, a small number of flg22induced genes are induced by DC3000 TTSS. This becomes more apparent at $24 \mathrm{~h}$ after inoculation. Consistent with a role of RAR1 in ETI, a significant number of defense-related genes, including many induced by flg22, are induced by DC3000 in a RAR1-dependent manner. Weak ETI may be common during compatible interactions, because virulent $P$. syringae pv. phaseolicola and $P$. syringae pv. syringae strains are known to carry certain effectors capable of triggering defenses in their susceptible host plants (Jackson et al. 1999; Vinatzer et al. 2006). Indeed, some Arabidopsis resistance genes have been shown to specify weak recognition of $P$. syringae effectors (Eitas et al. 2008; Kim et al. 2009). The possibility that DC3000 triggers ETI in Arabidopsis is consistent with an early report showing that plants treated with compatible and incompatible bacteria show similar expression profiles, with the compatible interaction showing delayed defense gene induction (Tao et al. 2003).

Compatible and nonhost interactions in this study differ mainly in the effectiveness of PTI, which plays a greater role in the latter interaction. Although it is often assumed that basal resistance during compatible interactions is induced by PAMPs, critical analysis is scarce. It appears that PTI primarily contributes to pre-penetration resistance to compatible $P$. syringae but is largely ineffective after bacteria have gained access to the apoplast. Arabidopsis fls 2 mutant plants lacking the receptor for flg22 show increased susceptibility to DC3000 when spray inoculated but normal susceptibility when bacteria are infiltrated into leaves (Zipfel et al. 2004). This is because
FLS2 triggers stomata closure upon the recognition of flagellin, and the fls 2 mutant permits better penetration by the bacteria (Melotto et al. 2006). Introduction of the fliC mutation into DC3000 or abrogation of PTI by expressing the HopAII transgene in plants do not further enhance DC3000 growth when bacteria were infiltrated into leaves ( $\mathrm{Li}$ et al. 2005) (Fig. 4B). This is likely because DC3000 effectors are highly effective in suppressing PAMP-induced defenses ( $\mathrm{Li}$ et al. 2005). In contrast, PTI acts in both pre- and post-penetration resistance during nonhost interactions ( $\mathrm{Li}$ et al. 2005; Melotto et al. 2006). First, the fliC mutation in P. syringae pv. tabaci 6505 significantly enhanced Arabidopsis susceptibility to strain 6505 (Li et al. 2005). Second, transgenic expression of HopAII compromised resistance to strain 6505 and $P$. syringae pv. phaseolicola NPS3121 but not DC3000 (Li et al. 2005) (Fig. 4). Although it is possible that HopAI1 also inhibits ETI, the differential effects of the HopAII transgene expression on basal resistance to DC3000 and the nonadapted strains are most consistent with a greater role of PTI in nonhost resistance. Strain 6505 effectors do not appear to collectively suppress PTI, as indicated by the identical PAMP-response gene expression in plants inoculated with WT and $h r c C^{-} 6505$ strains (Fig. 3). The differential roles of PTI during compatible and nonhost interactions are consistent with the notion that overcoming PTI plays a critical role in the adaptation of virulent pathogens to their host plants.

ETI alone does not explain the complete resistance in nonhost interactions. The disruption of ETI by rarl and $n d r l \mathrm{mu}-$ tations converts an incompatible interaction into a compatible one; however, the same mutations only modestly increase the P. syringae pv. tabaci 6505 or R1152 bacterial populations in plants. This is consistent with the notion that effectors in nonadapted bacteria are largely unable to inhibit PTI in Arabidopsis. Indeed, the combination of fliC mutation in $P$. syringae pv. tabaci 6505 and rarl-29, ndrl, or nhol mutation in the plant resulted in a near-compatible interaction. These results suggest that, when combined, PTI and ETI constitute powerful layers of resistance in this nonhost interaction. In addition, the ability of this bacterium to grow to a high level in immune-compromised plants indicates that the lack of presumed "compatibility factors" in nonadapted bacteria can be compensated for by the abrogation of PTI and ETI. In fact, $P$. syringae mutants lacking functional TTSS are capable of multiplying to high levels in transgenic plants expressing effectors that suppress PTI (Hauck et al. 2003; Kim et al. 2005). It can be deduced that the so-called "compatibility factors" are virulence factors that suppress host defenses. The combined effect of multilayered defenses has been seen for Arabidopsis nonhost resistance to Blumeria graminis f. sp. hordei, an obligated fungal pathogen that causes powdery mildew on barley. The pen $2 / e d s 1$ doublemutant plants compromised in both pre-penetration and postpenetration defenses are highly susceptible to this normally nonhost fungal pathogen (Lipka et al. 2005). Although the EDS1-mediated resistance is likely triggered by fungal effectors, there is evidence suggesting that the PEN2-mediated resistance is induced by PAMPs (Jones and Dangl 2006).

Often, basal resistance and PTI are used interchangeably. The work described here clearly showed that both PTI and ETI can contribute to basal resistance. This is consistent with the proposal put forward by Jones and Dangl (2006): "the most accurate definition of basal defense would be PTI plus weak ETI minus ETS" (effector-triggered susceptibility). Basal resistance, by definition, is a descriptive term that implies weak resistance. In contrast, PTI and ETI, which can be strong or weak, are mechanistically defined terms. We suggest that the use of basal resistance be limited to minimal resistance that remains mechanistically defined. 


\section{MATERIALS AND METHODS}

\section{Plants and bacterial strains.}

Five-week-old WT Col-0, ndrl, rarl-20, and rarl-29 mutants and HopAII transgenic plants (all in Col-0 background) were used for all experiments ( $\mathrm{Li}$ et al. 2005; Shang et al. 2006). Bacterial strains used included $P$. syringae pv. tomato DC3000, $P$. syringae pv. tabaci R1152, WT and fliC $C^{-} P$. syringae pv. tabaci 6505, and the WT $P$. syringae pv. phaseolicola NPS3121 and its $h r p A^{-}$derivative (Lu et al. 2001; Li et al. 2005).

To knockout the $h r c C$ gene in $P$. syringae pv. tabaci 6505, a TOPO: $h r c C$ plasmid was constructed by cloning an $h r c C$ partial open reading frame (ORF) into the TOPO TA cloning vector (Invitrogen). The $h r c C$-F primer (5'-TTG GTC AGG AAT ACC ACT TC- $\left.3^{\prime}\right)$ and the $h r c C$-R primer $\left(5^{\prime}\right.$-TGA TGA GTT TCT CGT ACA TCG-3') were used for amplifying the $h r c C$ partial ORF. The TOPO:hrcC plasmid was then introduced into $P$. syringae pv. tabaci 6505 by electroporation. Colonies with kanamycin and ampicillin resistance were selected and verified by diagnostic polymerase chain reaction analysis with the $h r c C$-Diag primer (5'-ATT TCA GTG AGT TCG CTG AG$\left.3^{\prime}\right)$ in combination with the T7 primer (5'-TAA TAC GAC TCA CTA TTG GG-3') or the SP6 primer (5'-TAT TTA GGT GAC ACT ATA G-3').

\section{HR and bacterial growth assay.}

Bacteria were syringe infiltrated into 5-week-old Arabidopsis plants at $10^{8} \mathrm{CFU} / \mathrm{ml}$ for HR assay. For bacterial growth assay, plants were syringe infiltrated with $10^{6} \mathrm{CFU} / \mathrm{ml}$ bacteria (or otherwise indicated).

\section{Northern analysis.}

Plants were infiltrated with bacteria at $10^{6} \mathrm{CFU} / \mathrm{ml}, \mathrm{H}_{2} \mathrm{O}$, or $1 \mu \mathrm{M}$ flg22 peptide, and leaves were collected at the indicated times for RNA isolation. Total RNA $(10 \mu \mathrm{g})$ was loaded in each lane and the RNA blot was hybridized with the indicated radio-labeled probes.

\section{Microarray analysis.}

WT or rarl-29 plants were treated with DC3000 for $24 \mathrm{~h}$ prior to RNA isolation. Each treatment contained three biological replicates. Affymetrix ATH1 arrays were used for hybridization. GCOS software and MAS5 algorithm were used for data collection and normalization. To analyze the differentially expressed genes between control and treatment, foldchange analysis and a one-way analysis of variance test were applied. $P$ value $\leq 0.05$ and fold change $\geq 2$ between treatment and control samples were considered as cut-off, and the induced or repressed genes were selected.

\section{ACKNOWLEDGMENTS}

J.-M. Zhou was supported by a grant from Chinese Ministry of Science and Technology (2003-AA210080).

\section{LITERATURE CITED}

Asai, T., Tena, G., Plotnikova, J., Willmann, M. R., Chiu, W. L., GomezGomez, L., Boller, T., Ausubel, F. M., and Sheen, J. 2002. MAP kinase signaling cascade in Arabidopsis innate immunity. Nature 415:977-983.

Ausubel, F. M. 2005. Are innate immune signaling pathways in plants and animals conserved? Nat. Immunol. 6:973-979.

Boller, T., and Felix, G. 2009. A renaissance of elicitors: Perception of microbe-associated molecular patterns and danger signals by pattern-recognition receptors. Annu. Rev. Plant Biol. 60:379-406.

Chen, H., Xue, L., Chintamanani, S., Germain, H., Lin, H., Cui, H., Cai, R., Zuo, J., Tang, X., Li, X., Guo, H., and Zhou, J. M. 2009. ETHYLENE INSENSITIVE3 and ETHYLENE INSENSITIVE3-LIKE1 repress
SALICYLIC ACID INDUCTION DEFICIENT2 expression to negatively regulate plant innate immunity in Arabidopsis. Plant Cell 21:2527-2540.

Chisholm, S. T., Coaker, G., Day, B., and Staskawicz, B. J. 2006. Hostmicrobe interactions: Shaping the evolution of the plant immune response. Cell 124:803-814.

Coppinger, P., Repetti, P. P, Day, B., Dahlbeck, D., Mehlert, A., and Staskawicz, B. J. 2004. Overexpression of the plasma membrane-localized NDR1 protein results in enhanced bacterial disease resistance in Arabidopsis thaliana. Plant J. 40:225-237.

Eitas, T. K., Nimchuk, Z. L., and Dangl, J. L. 2008. Arabidopsis TAO1 is a TIR-NB-LRR protein that contributes to disease resistance induced by the Pseudomonas syringae effector AvrB. Proc. Natl. Acad. Sci. U.S.A. 105:6475-6480.

Espinosa, A., Guo, M., Tam, V. C., Fu, Z. Q., and Alfano, J. R. 2003. The Pseudomonas syringae type III-secreted protein HopPtoD2 possesses protein tyrosine phosphatase activity and suppresses programmed cell death in plants. Mol. Microbiol. 49:377-387.

Guo, M., Tian, F., Wamboldt, Y., and Alfano, J. R. 2009. The majority of the type III effector inventory of Pseudomonas syringae pv. tomato DC3000 can suppress plant immunity. Mol. Plant-Microbe Interact. 22:1069-1080.

Ham, J. H., Kim, G. K., Lee, S. Y., and Mackey, D. 2007. Layered basal defenses underlie non-host resistance of Arabidopsis to Pseudomonas syringae pv. phaseolicola. Plant J. 51:604-616.

Hauck, P., Thilmony, R., and He, S. Y. 2003. A Pseudomonas syringae type III effector suppresses cell wall-based extracellular defense in susceptible Arabidopsis plants. Proc. Natl. Acad. Sci. U.S.A. 100:85778582 .

Holt, B. F., Belkhadir, Y., and Dangl, J. L. 2005. Antagonistic control of disease resistance protein stability in the plant immune system. Science 309:929-932.

Jackson, R. W., Athanassopoulos, E., Tsiamis, G., Mansfield, J. W., Sesma, A., Arnold, D. L., Gibbon, M. J., Murillo, J., Taylor, J. D., and Vivian, A. 1999. Identification of a pathogenicity island, which contains genes for virulence and avirulence, on a large native plasmid in the bean pathogen Pseudomonas syringae pathovar phaseolicola. Proc. Natl. Acad. Sci. U.S.A. 96:10875-10880.

Jones, J. D., and Dangl, J. L. 2006. The plant immune system. Nature 444:323-339.

Kang, L., Li, J., Zhao, T., Xiao, F., Tang, X., Thilmony, R., He, S., and Zhou, J. M. 2003. Interplay of the Arabidopsis nonhost resistance gene NHO1 with bacterial virulence. Proc. Natl. Acad. Sci. U.S.A. 100:35193524.

Kim, M. G., da Cunha, L., McFall, A. J., Belkhadir, Y., DebRoy, S., Dangl, J. L., and Mackey, D. 2005. Two Pseudomonas syringae type III effectors inhibit RIN4-regulated basal defense in Arabidopsis. Cell 121:749759.

Kim, M. G., Geng, X., lee, S. Y., and Mackey, D. 2009. The Pseudomonas syringae type III effector AvrRpm1 induces significant defenses by activating the Arabidopsis nucleotide-binding leucine-rich repeat protein RPS2. Plant J. 57:645-653.

Li, X., Lin, H., Zhang, W., Zou, Y., Zhang, J., Tang, X., and Zhou, J. M. 2005. Flagellin induces innate immunity in nonhost interactions that is suppressed by Pseudomonas syringae effectors. Proc. Natl. Acad. Sci. U.S.A. 102:12990-12995.

Lipka, V., Dittgen, J., Bednarek, P., Bhat, R., Wiermer, M., Stein, M., Landtag, J., Brandt, W., Rosahl, S., Scheel, D., Llorente, F., Molina, A., Parker, J., Somerville, S., and Schulze-Lefert, P. 2005. Pre- and postinvasion defenses both contribute to nonhost resistance in Arabidopsis. Science 310:1180-1183.

Lorang, J. M., Shen, H., Kobayashi, D., Cooksey, D., and Keen, N. T. 1994. avrA and avrE in Pseudomonas syringae pv. tomato PT23 play a role in virulence on tomato plants. Mol. Plant-Microbe Interact. 7:508515.

Lu, M., Tang, X., and Zhou, J. M. 2001. Arabidopsis NHO1 is required for general resistance against Pseudomonas bacteria. Plant Cell 13:437447.

Melotto, M., Underwood, W., Koczan, J., Nomura, K., and He, S. Y. 2006. Plant stomata function in innate immunity against bacterial invasion. Cell 126:969-980.

Navarro, L., Zipfel, C., Rowland, O., Keller, I., Robatzek, S., Boller, T. and Jones, J. D. G. 2004. The transcriptional innate immune response to flg22. Interplay and overlap with $A v r$ gene-dependent defense responses and bacterial pathogenesis. Plant Physiol. 135:1113-1128.

Nürnberger, T., and Lipka, V. 2005. Non-host resistance in plants: New insights into an old phenomenon. Mol. Plant Pathol. 6:335-354.

Qutob, D., Kemmerling, B., Brunner, F., Kufner, I., Engelhardt, S., Gust, A. A., Luberacki, B., Seitz, H. U., Stahl, D., Rauhut, T., Glawischnig, E., Schween, G., Lacombe, B., Watanabe, N., Lam, E., Schlichting, R., 
Scheel, D., Nau, K., Dodt, G., Hubert, D., Gijzen, M., and Nürnberger T. 2006. Phytotoxicity and innate immune responses induced by Nep1like proteins. Plant Cell 18:3721-3744.

Shang, Y., Li, X., Cui, H., He, P., Thilmony, R., Chintamanani, S., ZwieslerVollick, J., Gopalan, S., Tang, X., and Zhou, J. M. 2006. RAR1, a central player in plant immunity, is targeted by Pseudomonas syringae effector AvrB. Proc. Natl. Acad. Sci. U.S.A. 103:19200-19205.

Tao, Y., Xie, Z., Chen, W., Glazebrook, J., Chang, H. S., Han, B., Zhu, T., Zou, G., and Katagiri, F. 2003. Quantitative nature of Arabidopsis responses during compatible and incompatible interactions with the bacterial pathogen Pseudomonas syringae. Plant Cell 15:317-330.

Thordal-Christensen, H. 2003. Fresh insights into processes of nonhost resistance. Curr. Opin. Plant Biol. 6:351-357.

Truman, W., de Zabala, M. T., and Grant, M. 2006. Type III effectors orchestrate a complex interplay between transcriptional networks to modify basal defence responses during pathogenesis and resistance. Plant J. 46:14-33.

Vinatzer, B. A., Teitzel, G. M., Lee, M. W., Jelenska, J., Hotton, S., Fairfax, K., Jenrette, J., and Greenberg, J. T. 2006. The type III effector repertoire of Pseudomonas syringae pv. syringae $\mathrm{B} 728 \mathrm{a}$ and its role in survival and disease on host and non-host plants. Mol. Microbiol. 62:26-44.

Warren, R. F., Merritt, P. M., Holub, E., and Innes, R. W. 1999. Identification of three putative signal transduction genes involved in $\mathrm{R}$ genespecified disease resistance in Arabidopsis. Genetics 152:401-412.

Wei, C. F., Kvitko, B. H., Shimizu, R., Crabill, E., Alfano, J. R., Lin, N.
C., Martin, G. B., Huang, H. C., and Collmer, A. 2007. A Pseudomonas syringae pv. tomato DC3000 mutant lacking the type III effector HopQ1-1 is able to cause disease in the model plant Nicotiana benthamiana. Plant J. 51:32-46.

Zhang, J., Shao, F., Li, Y., Cui, H., Chen, L., Li, H., Zou, Y., Lan, L., Chai, J., Tang, X., and Zhou, J. M. 2007. A Pseudomonas syringae effector inactivates MAPKs to suppress PAMP-induced immunity in plants. Cell Host Microbe 1:175-185.

Zipfel, C. 2009. Early molecular events in PAMP-triggered immunity. Curr. Opin. Plant Biol. 12:414-420.

Zipfel, C., Robatzek, S., Navarro, L., Oakeley, E. J., Jones, J. D., Felix, G., and Boller, T. 2004. Bacterial disease resistance in Arabidopsis through flagellin perception. Nature 428:764-767.

Zwiesler-Vollick, J., Plovanich-Jones, A. E., Nomura, K., Bandyopadhyay, S., Joardar, V., Kunkel, B. N., and He, S. Y. 2002. Identification of novel hrp-regulated genes through functional genomic analysis of the Pseudomonas syringae pv. tomato DC3000 genome. Mol. Microbiol. 45:12071218

\section{AUTHOR-RECOMMENDED INTERNET RESOURCE}

The Arabidopsis Information Resource AtGenExpress database: www.arabidopsis.org/servlets/TairObject?type=expression_set\&id=100 7966202 